\title{
Clinical evaluation of anatomical reconstruction of the anterior cruciate ligament
}

\author{
V.V. Zayats, A.K. Dulaev, A.V. Dydykin, I.N. Ulyanchenko \\ Pavlov First St. Petersburg State Medical University, Saint Petersburg, Russian Federation
}

\begin{abstract}
Purpose Evaluate clinical effectiveness of anatomical reconstruction of the anterior cruciate ligament (ACL) and determine the perspectives for practical health care. Material and methods The review included 706 patients who underwent arthroscopic reconstruction of the ACL and graft interference screw fixation between 2010 and 2018. ACL reconstruction was performed using either anteromedial portal ( $\mathrm{n}=396$, Group I) or an isometric transtibial tunnel technique ( $\mathrm{n}=310$, Group II). Outcomes were evaluated clinically and radiographically using the 2000 International Knee Documentation Committee (2000 IKDC) Subjective Knee Evaluation Form, the Knee Injury and Osteoarthritis Outcome Score (KOOS) and the Tegner Lysholm scoring scale. Clinical and economic outcome measures included surgical time, rehabilitation and disability periods and period of recovery for sports performance. Results The knee anterior drawer test was equally negative and showed no significant differences in the groups. The Lachman test and the pivot shift test showed better results in Group I $(p<0.001)$. Contractures, atrophic femoral muscles $(\mathrm{p}<0.05)$, synovitis $(\mathrm{p}<0.01)$, vertical position of the femoral graft channels and pathologically extended bone channels with wind-wiper effect $(\mathrm{p}<0.001)$ were more common among patients of Group II. Although knee function returned to normal, as rated with the 2000 IKDC Subjective Knee Evaluation Form, in $91.3 \%$ of cases pathological changes in the knee (C) and severely impaired function (D) were 2.5 and 5 times less common in Group I than in Group II ( $p<$ $0.05)$. Pain, symptoms and sport scores were significantly higher on the KOSS scale for Group I $(\mathrm{p}<0.05)$. Surgical time was longer in patients of Group I $(p<0.05)$ who had shorter rehabilitation period $(p<0.05)$. Conclusion Anatomical reconstruction of ACL using anteromedial portal was shown to be a more reliable technique as compared to transtibial approach to ensure overall knee stability arranging adequate bone channels. The technique is capable to protect the graft from injury, reduce the likelihood of pain, synovitis, contractures, muscle atrophy, providing shorter rehabilitation, disability period and recovery for sport performance.
\end{abstract}

Keywords: anatomical reconstruction of the anterior cruciate ligament (ACL), transtibial portal, anterior instability of the knee joint, sport activity

\section{INTRODUCTION}

The treatment of anterior cruciate ligament (ACL) rupture has significantly evolved over the past two decades with technological advances allowing anatomic reconstruction. Two basic principles of ACL reconstruction formulated more than 20 years ago involved an isometric technique using a transtibial approach through the tibial bone tunnel, and anatomical approach aimed at imitating the natural course of the native ligament fibers [1, 2]. Following the same concept of anatomical ACL reconstruction, the use of a double-bundle graft was proposed with the employment of "Y"-plasty [3, 4]. The reasons that encouraged orthopaedic and trauma surgeons work towards this problem were associated with increasing incidence of knee and ACL injury, technological advances, the patients' wishes for a complete functional recovery to help keeping them

mobile in the long term and allowing return to sports and exercise activity that would translate into a higher quality of life. Despite the large number of publications reporting multiple surgical and different operative techniques and approaches, a systematic review of the clinical effectiveness of anatomical reconstruction of ACL requires further justification $[5,6]$. Several areas of controversy exist in ACL tear management with the lack of comparative research $[6,7]$ which have engaged surgeons and researchers in debates towards identifying an ideal isometric and anatomical approach for these patients.

Purpose Evaluate clinical effectiveness of anatomical reconstruction of the ACL using anteromedial portal (AMP) compared to conventional transtibial anterior cruciate reconstruction, and determine the possibilities for clinical use.

\section{MATERIAL AND METHODS}

Written informed consent for the participation in the research project was obtained from each subject. The study was performed in accordance with ethical principles for medical research involving human subjects stated in the Declaration of Helsinki

developed by the World Medical Association as revised in 2013. The study received a favorable opinion from the relevant research ethics committee.

Inclusion criteria included patients aged 18 to 35 years with total ACL tear (confirmed with physical 
examination, MR images and during arthroscopic visualization of the knee joint), full range of motion in the knee joint at the time of surgery who underwent transtibial ACL reconstruction or through AMP with BTB, ST, Q autografts fixed with interference screws no earlier than one month of injury. Patients who had ACL tear and associated injury to posterior cruciate ligament and/or collateral ligaments and/or hamstring tendons, deep traumatic cartilage defects up to the subchondral bone or grade 4 chondromalacia of the knee at the time of surgery, those who underwent ACL reconstruction using a synthetic implant or allograft fixed with cortical or transcanal screws were excluded from the study.

A total of 706 patients who underwent arthroscopic ACL reconstruction between 2010 and 2018 were recruited for the study. Group I included 396
(56.1\%) patients who underwent anatomical ACL reconstruction through AMP, and group II consisted of $310(43.9 \%)$ patients treated with isometric transtibial ACL reconstruction. Both groups were comparable by sex, age, mechanism of injury, time of injury, application rate of different autografts (Table 1).

Arthroscopic ACL reconstructions including autograft harvesting were performed using standard techniques. AMP was placed $1-1.5 \mathrm{~cm}$ inferior and $1.5-2 \mathrm{~cm}$ medial of the standard medial arthroscopic approach right over the anterior horn of the medial meniscus bypassing the medial femoral condyle with AMP placement regulating through the anterolateral arthroscopic approach. Comparative characteristics of anatomical and isometric surgical techniques are presented in Table 2.

Table 1

Characterization of study groups

\begin{tabular}{|c|c|c|c|c|}
\hline Description & Group I (n=396) & Group II $(n=310)$ & $\mathrm{p}^{1}$ & Total $(n=706)$ \\
\hline Male & $193(48.7 \%)$ & $132(42.6 \%)$ & $\mathrm{p}=0.3207$ & $325(46.0 \%)$ \\
\hline Female & $203(51.3 \%)$ & $178(57.4 \%)$ & $\mathrm{p}=0.3742$ & $381(54.0 \%)$ \\
\hline Age (years) & $31.4 \pm 2.3$ & $32.1 \pm 1.1$ & $\mathrm{p}=0.428$ & $31.9 \pm 1.4$ \\
\hline Sport related injury & $312(78.8 \%)$ & $224(72.3 \%)$ & $\mathrm{p}=0.4551$ & $536(75.9 \%)$ \\
\hline Non-sport related injury & $84(21.2 \%)$ & $86(27.7 \%)$ & $\mathrm{p}=0.1376$ & $170(24.1 \%)$ \\
\hline Injury to other articular components & $318(80.3 \%)$ & $257(82.9 \%)$ & $\mathrm{p}=0.7781$ & $575(81.4 \%)$ \\
\hline \multicolumn{5}{|c|}{ Autograft } \\
\hline$-\mathrm{BTB}$ & $181(45.7 \%)$ & $165(53.2 \%)$ & $\mathrm{p}=0.2473$ & $346(49.0 \%)$ \\
\hline$-\mathrm{ST}$ & $197(49.7 \%)$ & $134(43.2 \%)$ & $\mathrm{p}=0.2986$ & $332(47.0 \%)$ \\
\hline$-\mathrm{Q}$ & $18(4.5 \%)$ & $11(3.5 \%)$ & $\mathrm{p}=0.5247$ & $29(4.1 \%)$ \\
\hline \multicolumn{5}{|c|}{ Time point } \\
\hline Less than 6 months & $101(25.5 \%)$ & $68(21.9 \%)$ & $\mathrm{p}=0.3866$ & $169(23.9 \%)$ \\
\hline $6-12$ months & $161(40.7 \%)$ & $138(44.5 \%)$ & $\mathrm{p}=0.5128$ & $299(42.3 \%)$ \\
\hline $1-3$ years & $62(15.7 \%)$ & $46(14.8 \%)$ & $\mathrm{p}=0.5128$ & $108(15.3 \%)$ \\
\hline $3-5$ years & $41(10.4 \%)$ & $32(10.3 \%)$ & $\mathrm{p}=0.9904$ & $73(10.3 \%)$ \\
\hline More than 5 years & $31(7.8 \%)$ & $26(8.4 \%)$ & $\mathrm{p}=0.8031$ & $57(8.1 \%)$ \\
\hline
\end{tabular}

Notes: ${ }^{1}$ no differences in parameters found between the groups according to Fisher test; BTB, bone-tendon-bone graft harvested from the mid portion of the patellar tendon; ST, semitendinous and gracilis; Q, quadriceps

Table 2

Comparison of anatomical and transtibial ACL reconstructions

\begin{tabular}{|c|c|c|}
\hline \multirow{2}{*}{ Description } & \multicolumn{2}{|c|}{ Type of ACL reconstruction } \\
\hline & anatomical & transtibial \\
\hline Graft position & imitate native ACL & vertical ACL graft \\
\hline \multicolumn{3}{|c|}{ Femoral tunnel } \\
\hline Positioning & $\begin{array}{l}\text { center of native ACL, medial aspect of the } \\
\text { lateral femoral condyle }\end{array}$ & $\begin{array}{l}\text { Proximally and anteriorly of the native ACL, } \\
\text { posterior/posterior-medial aspect of the lateral } \\
\text { femoral condyle }\end{array}$ \\
\hline Technique used & Additional portal & Via tibial tunnel \\
\hline Femoral tunnel guide & optional & needed \\
\hline Length, mm & $20-35$ & $40-50$ \\
\hline Vertical angle, ${ }^{\circ}$ & $40-65$ & $30-45$ \\
\hline Plasty of the femoral intercondylar notch & Not common & common \\
\hline \multicolumn{3}{|c|}{ Tibial tunnel } \\
\hline Positioning & center of native ACL & Posterior portion of the ACL attachment \\
\hline Purpose & Fixation of the tibial graft & $\begin{array}{l}\text { - femoral tunnel drilling; } \\
\text { - fixation of the tibial graft }\end{array}$ \\
\hline Diameter and configuration & Precisely matching graft diameter & $\begin{array}{l}\text { Being greater than the graft diameter is common } \\
\text { expanding at femoral tunnel drilling }\end{array}$ \\
\hline
\end{tabular}


Surgical outcomes were evaluated with standard physical tests using the International Knee Documentation Committee 2000 subjective knee form (IKDC 2000), Knee Injury and Osteoarthritis Outcome Score (KOOS) and the Tegner Lysholm scale $[8,9,10]$. Magnetic resonance imaging was performed for 653 patients $(96.9 \%)$ and computer tomography was performed for 427 patients $(63.4 \%)$. The imaging evaluation included morphometry used to measure positioning, internal and external drilling diameters, length, and inclination angles of bone tunnels [11-17]. Clinical and economic assesment included the time of surgical intervention, the total operating time, use-of-crutches time, external immobilization with hinges, rehabilitation and disability periods, full recovery of daily and sport activity. Statistical data analysis was performed using STATISTICA 5.5 computer program (licence № AXXR402C295023FAN4) and Fisher test was used to identify significant differences.

\section{RESULTS}

Postoperative physical examination of the knee showed high stability of the joint in both groups. Anterior drawer test demonstrated tibia translation of at least $2 \mathrm{~mm}$ in $77.3 \%$ of patients and $5 \mathrm{~mm}$, in $96.7 \%$. There were no differences between groups I and II. However, in the Lachman test, "0" and " $1+$ " were more common for group I ( $84.6 \%$ and $12.4 \%$, respectively) than for group II $(63.2 \%(\mathrm{p}<0.05)$ and $26.5 \%$ $(\mathrm{p}<0.001)$, respectively). Anterior translation of the knee rated as "2" was seen in group II ( $5.8 \%$ and $2.3 \%$, respectively $(p<0.05))$. The differences between the study groups were more significant in the assessment of the rotational stability of the knee. Pivot-shift test demostrated no case of pronounced anterolateral rotatory instability of the knee in group I, with $12.9 \%$ $(p<0.001)$ of the cases rated as not pronounced and $2.0 \%$ as moderately pronounced and the knee was stable in the remaining $85.1 \%$. The percentages in group I were much better than in group II featuring stable knee in $55.2 \%(p<0.001)$, anterolateral rotatory instability of the knee being not pronounced in $31.3 \%(\mathrm{p}<0.001)$, moderately pronounced in $8.7 \%$ $(\mathrm{p}<0.001)$ and pronounced in $4.8 \%(\mathrm{p}<0.001)$ of cases. Comparative clinical evaluation of postoperative knee stability in groups I and II is presented in Table 3.

In addition to that, group II demonstrated more cases of flexion or combined contractures of the knee joint with $26(8.7 \%)$ vs. $5(1.3 \%)$ in group I $(\mathrm{p}<0.01)$, synovitis $(41(13.2 \%)$ vs. $10(2.5 \%)$, respectively $(p<0.001)$ and femoral muscle atrophy of more than $1.5 \mathrm{~cm}$ as compared to the opposite $\operatorname{limb}(54(17.4 \%)$ vs. $21(5.3 \%)$, respectively $(\mathrm{p}<0.05))$. Morphometry based on MRI or CT finding revealed much more cases of femoral tunnel position rated as unacceptable in group II (89 $(29.7 \%)$ vs. $16(4.0 \%)$ in group I, $\mathrm{p}<0.001)$, inappropriate vertical autograft course $(41(13.2 \%)$ vs. $3(0.8 \%)$ in group I, $\mathrm{p}<0.001)$, destructed or defrayed autograft (54 (17.4\%) vs. $14(3.5 \%)$ in group I, $\mathrm{p}<0.001)$, pathological expansion of inner openings in bone tunnels by more than $3 \mathrm{~mm}$ seen as a "wiper effect" (112 (36.1\%) vs 14 (3.5\%) in group I, $\mathrm{p}<0.001)$. IKDC 2000 subjective knee form showed $91.6 \%$ of patients who could grade symptoms at the high activity level. Poor results rated as $\mathrm{C}$ and $\mathrm{D}$ on 2000 IKDC scale were seen in $8.4 \%$ of patients. There were significant differences in IKDC scores between the groups with ' $\mathrm{C}$ ' IKDC score being 3 times less common for group I than for group II ( $2.3 \%$ and $9.3 \%$, respectively, $\mathrm{p}<0.001$ ), and severe functional impairment ('D' IKDC score) being 6 times less common for group I than for group II $(0.7 \%$ and $5.8 \%$, respectively $(\mathrm{p}<0.001))$.

Table 3

Comparative clinical evaluation of postoperative knee stability in groups I and II

\begin{tabular}{|c|c|c|c|c|}
\hline Description & Group I & Group II & $\mathrm{p}$ & Total \\
\hline \multicolumn{5}{|c|}{ Anterior drawer test } \\
\hline $0(0-2 \mathrm{~mm})$ & $312(78.8 \%)$ & $234(75.5 \%)$ & $\mathrm{p}=0.7095$ & $546(77.3 \%)$ \\
\hline $1^{+}(3-5 \mathrm{~mm})$ & $72(18.2 \%)$ & $65(21.0 \%)$ & $\mathrm{p}=0.4460$ & $137(19.4 \%)$ \\
\hline $2^{+}(6-10 \mathrm{~mm})$ & $12(3.0 \%)$ & $11(3.5 \%)$ & $\mathrm{p}=0.7096$ & $23(3.3 \%)$ \\
\hline $3^{+}(>10 \mathrm{~mm})$ & - & - & - & - \\
\hline \multicolumn{5}{|c|}{ Lachman test } \\
\hline $0(1-2 \mathrm{~mm})^{*}$ & $335(84.6 \%)^{+}$ & $196(63.2 \%)$ & $\mathrm{p}<0.05$ & $531(75.2 \%)$ \\
\hline $1^{+}(3-5 \mathrm{~mm})^{*}$ & $49(12.4 \%)^{+}$ & $82(26.5 \%)$ & $\mathrm{p}<0.001$ & $131(18.6 \%)$ \\
\hline $2^{+}(6-10 \mathrm{~mm})$ & $9(2.3 \%)$ & $18(5.8 \%)$ & $\mathrm{p}<0.05$ & $27(3.8 \%)$ \\
\hline $3^{+}(>10 \mathrm{~mm})$ & $3(0.7 \%)$ & $14(4.5 \%)$ & $\mathrm{p}<0.05$ & $17(2.4 \%)$ \\
\hline \multicolumn{5}{|c|}{ Pivot-shift test } \\
\hline 0 (instability not identified)* & $337(85.1 \%)^{+}$ & $171(55.2 \%)$ & $\mathrm{p}<0.001$ & $508(71.9 \%)$ \\
\hline $1^{+}$(instability not pronounced)* & $51(12.9 \%)^{+}$ & $97(31.3 \%)$ & $\mathrm{p}<0.001$ & $148(21.0 \%)$ \\
\hline $2^{+}$(instability moderately pronounced)* & $8(2.0 \%)^{+}$ & $27(8.7 \%)$ & $\mathrm{p}<0.001$ & $35(5.0 \%)$ \\
\hline $3^{+}$(instability pronounced)* & $0^{+}$ & $15(4.8 \%)$ & $\mathrm{p}<0.001$ & $15(2.1 \%)$ \\
\hline
\end{tabular}

Notes: *statistically significant differences; ${ }^{+}$the method differs for the better. 
Pain and symptom scores on KOSS scale were better for group I $(\mathrm{p}<0.05)$ than for group II measuring $85.1 \pm 1.6$ and $77.1 \pm 1.3 ; 84.1 \pm 2.4$ and $71.3 \pm 1.1$, respectively. Sport activity was also significantly higher in group I than in group II $(66.4 \pm 1.1$ versus $56.1 \pm 1.4$ in group II, $p<0.05)$ and resultant quality of life showing better scores in group I $(64.2 \pm 2.1$ versus $56.1 \pm 1.4$ in group II, $p<0.01$ ). Postopertaive knee function as measured with different scales in the patients is presented in Table 4 .

The average time of surgical intervention and the average operating time were significantly greater in group I than in group II measuring $89.1 \pm 2.8$ minutes and $79.6 \pm 3.1$ minutes; $121.9 \pm 4.1$ minutes and $114.6 \pm 2.9$ minutes, respectively $\quad(p<0.05)$. Rehabilitation periods were significantly shorter in group I than in group II $(4.1 \pm 0.4$ weeks vs. $5.5 \pm 0.9$ weeks, respectively, $\mathrm{p}<0.05)$, as well as disability periods $(10.4 \pm 0.3$ weeks and $11.9 \pm 0.1$ weeks, respectively, $\mathrm{p}<0.05)$ and return to sports and full physical activity $(40.9 \pm 1.9$ weeks and $44.1 \pm 1.8$ weeks, respectively, $\mathrm{p}<0.05$ ). Patients of group I underwent reoperations for different reasons including knee re-injury that were 3.5 times less common than those in group II $(11(2.7 \%)$ vs. $40(12.9 \%)$, respectively, $\mathrm{p}<0.01)$.

Table 4

Postopertaive knee function as measured with different scales in Groups I and II

\begin{tabular}{|c|c|c|c|c|}
\hline Description & Group I & Group II & $\mathrm{p}$ & Total \\
\hline \multicolumn{5}{|c|}{$2000 \mathrm{IKDC}$} \\
\hline A & $264(66.7 \%)$ & $181(58.4 \%)$ & $\mathrm{p}=0.2798$ & $445(63.0 \%)$ \\
\hline $\mathrm{B}$ & $120(30.3 \%)$ & $82(26.5 \%)$ & $\mathrm{p}=0.4016$ & $202(28.6 \%)$ \\
\hline $\mathrm{C}^{*}$ & $9(2.3 \%)^{+}$ & $29(9.3 \%)$ & $\mathrm{p}<0.001$ & $38(5.4 \%)$ \\
\hline $\mathrm{D}^{*}$ & $3(0.7 \%)^{+}$ & $18(5.8 \%)$ & $\mathrm{p}<0.001$ & $21(3.0 \%)$ \\
\hline \multicolumn{5}{|c|}{ KOSS } \\
\hline Pain* & $85.1 \pm 1.6^{+}$ & $77.1 \pm 1.3$ & $\mathrm{p}<0.05$ & - \\
\hline Symptoms (mean score)* & $84.1 \pm 2.4^{+}$ & $71.3 \pm 1.1$ & $p<0.05$ & - \\
\hline Daily activity (mean score) & $88.9 \pm 1.4$ & $86.2 \pm 2.1$ & $\mathrm{p}=0.224$ & - \\
\hline Sport activity (mean score)* & $66.4 \pm 1.1^{+}$ & $56.1 \pm 1.4$ & $\mathrm{p}<0.05$ & - \\
\hline Quality of life (mean score)* & $64.2 \pm 2.1^{+}$ & $57.2 \pm 1.7$ & $\mathrm{p}<0.01$ & - \\
\hline \multicolumn{5}{|c|}{$\begin{array}{l}1 \\
\text { Tegner Lysholm scale }\end{array}$} \\
\hline Score & $96.6 \pm 1.7$ & $91.2 \pm 1.3$ & $\mathrm{p}<0.05$ & - \\
\hline
\end{tabular}

Notes: *statistically significant differences; ${ }^{+}$the method differs for the better

\section{DISCUSSION}

Key factors for the success of ACL reconstructions include an adequately tailored choice of the graft, appropriate placement of the femoral and tibial tunnles, effective ACL graft tensioning, strong fixation to be secured throughout the healing period $[18,19]$. Anatomic ACL graft placement is defined as positioning the ACL femoral and tibial bone tunnels at the center of the native ACL femoral and tibial attachment sites [7, 8]. The ACL femoral tunnel is drilled independently of the tibial tunnel, which results in consistent placement of the femoral tunnel within the native ACL femoral attachment site (Fig. 1) [17, 20, 21].

In the transtibial technique, ACL graft tensioning is critical to the success of the procedure as well placed ('isometric') grafts appear to restore almost normal knee kinematics [22]. The applied technique of isometric graft placement is achieved by coaxial drilling of bone tunnels when they are either on the same line or close to it (Fig. 2).

Our findings suggested that anatomic ACL reconstruction was shown to be effective allowing to obtain good stability of the knee joint in $97.0 \%$ of cases. This is in line with the data of other authors who reported positive results in $96.5 \%$. However, in 2016, Kilinc B.E. et al. reported knee stability regained in $55.5 \%$ of patients after transtibial ACL reconstruction being equal to pre-injury level [17].

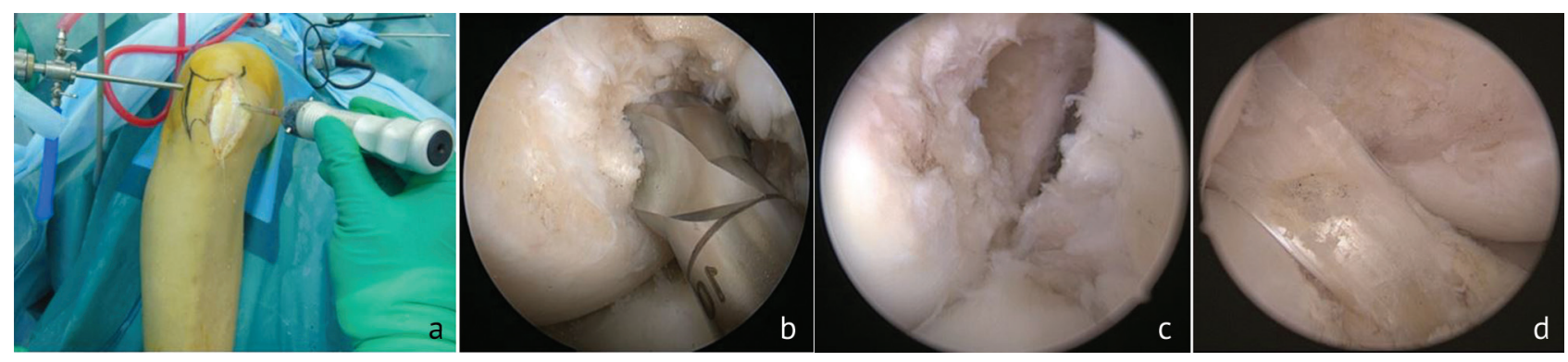

Fig. 1 Stages of surgical intervention in patients of group I showing (a) placement of femoral guide via AMP; (b) drilling femoral tunnel using a guide pin; (c) placement of the femoral tunnel on the medial aspect of the lateral femoral condyle; (d) appearance of the graft placed at the center of the native ACL 


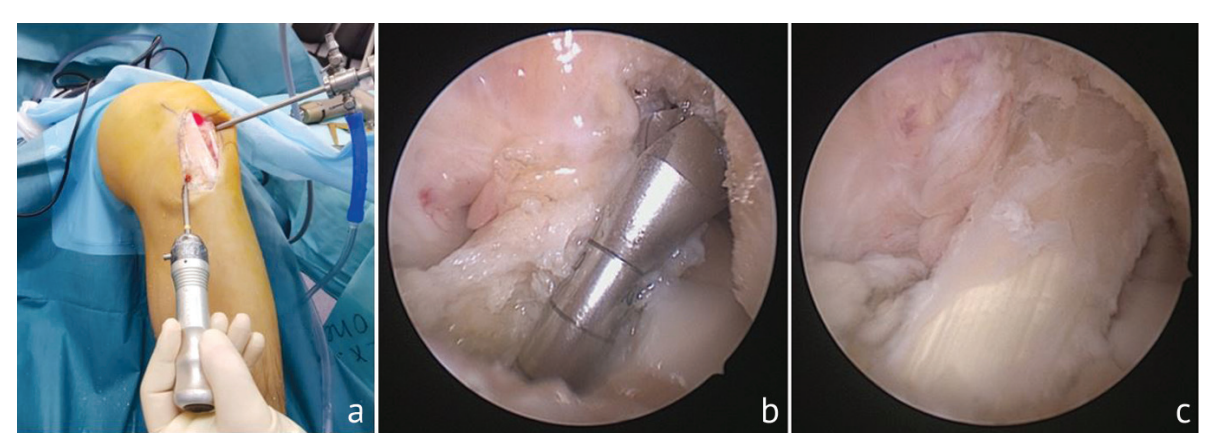

Fig. 2 Stages of isometric/transtibial ACL reconstruction showing (a) placement of femoral guide via tibial tunnel; (b) drilling the femoral tunnel; $(\boldsymbol{c})$ appearance of isometric graft

This could be ascribed to the use of the semitendinous and gracilis tendons of a smaller diameter that resulted in a smaller overlapping area of the native ACL femoral and tibial attachment sites as compared to patellar tendon and quadriceps. In our opinion, transtibial ACL reconstruction can also be an effective technique if adequately performed, with the reliability of $84.9 \%$. Zhang L. et al. (2019) [23] reported the effectiveness of both techniques. Our patients showed no significant differences in function, return to activity and exercises after transtibial and anatomical ACL reconstruction at a 10-year follow-up. There were statistical differences between the groups of patients whose outcomes were rated as poor with the majority of transtibial cases $(p<0.001)$. Many authors report significant rotational stability of the knee joint due to anatomical ACL reconstruction $(p<0.05)[24,25,26]$. In our series, we also observed improved anterolateral rotatory stability of the knee at a greater statistical difference of $p<0.001$. A greater rotational stability of the knee provided by anatomical ACL reconstruction suggests that the multidirectional course of the graft fibers can simulate the multi-bundle structure of the native ACL and, thus, ensure adequate, more complicated, multivector movements of tibia.

Worse Lachman score of transtibial ACL reconstructions could be indicative of failures in isometric grafts in some patients who experienced insufficiency at the extreme arc of motion caused by low-amplitude anteror-posterior instability, $\mathrm{p}<0.05$. Similar results were reported by some authors with no reasons provided $[25,27]$. The complexity of the isometric graft positioning to prevent impingement in the intercondylar notch translated into an adverse event noted in group II as an unacceptable position of the femoral tunnel, inappropriate vertical autograft course, destructed or defrayed autograft, pathological expansion of inner openings in bone tunnels as a "wiper effect" $(p<0.001)$. Destruction of bone tunnels is mostly reported to be associated with transtibial reconstruction $[20,28]$. In addition to that, the inclination angle of the femoral tunnel of about $58^{\circ}$ in transtibial ACL reconstruction was shown to provide conditions for the vertical graft with resultant joint contracture or graft destruction [29, 30]. Failure to achieve proper stability of the knee joint in combination with autograft impingement was responsible for more frequent cases of synovitis and femur muscle atrophy in this group $(\mathrm{p}<0.001$ and $p<0.05$, respectively) and translated into lower functional knee scores after surgery [23].

However, anatomical ACL reconstruction appeared to be time consuming and highly demanding due to the increased number of surgical elements involved, $p<0.05$. Although the criterion has not been reported in the available literature, it has been found to be critical for economic aspect of treatment of the anterior knee instability with larger patient flow or at the training of young specialists. Reoperation rate in our series was nearly 3.5 times less than in the transtibial group with better functional results of anatomical ACL reconstruction provided through AMP. Reoperation rate was reported to range between 4.4 and $8.2 \%$ [31, 32]. It should be noted that all reoperations in patients with transtibial approach were performed at one stage using anatomical ACL reconstruction through AMP without any technical difficulties.

\section{CONCLUSION}

1. Transtibial and anatomical ACL reconstruction through AMP were shown to be reliable for restoring the stability of the knee joint $(84.9 \%$ and $97.0 \%$, respectively) with anatomical approach providing statistically better results for both the anterior- posterior (Lachman test, $\mathrm{p}<0.05$ ) and rotational (pivot-shift test, $\mathrm{p}<0.001$ ) stability.

2. Failure to achieve isometric graft in transtibial ACL reconstruction appeared to be the main cause of early postoperative knee instability $(\mathrm{p}<0.05)$ that led to 
secondary changes in bone tunnels, graft and meniscus destruction, and progression of osteoarthritis $(\mathrm{p}<0.001)$.

3. Patients who underwent anatomical ACL reconstruction through AMP were 3.5 times less likely to be reoperated $(\mathrm{p}<0.01)$ as compared to patients who underwent the transtibial approach. Anatomical ACL reconstruction through AMP was shown to be an effective procedure for revision.

\section{REFERENCES}

1. Abebe E.S., Moorman C.T. 3rd, Dziedzic T.S., Spritzer C.E., Cothran R.L., Taylor D.C., Garret W.E. Jr., DeFrate L.E. Femoral tunnel placement during anterior cruciate ligament reconstruction: an in vivo imaging analysis comparing transtibial and 2-incision tibial tunnel-independent techniques. Am. J. Sports Med., 2009, vol. 37, no. 10, pp. 1904-1911. DOI:10.1177/0363546509340768

2. Aglietti P., Zaccherotti G., Menchetti P.P., De Biase P. A comparison of clinical and radiological parameters with two arthroscopic techniques for anterior cruciate ligament reconstruction. Knee Surg. Sports Traumatol. Arthrosc., 1995, vol. 3, no. 1, pp. 2-8. DOI:10.1007/BF01553517

3. Bernard M., Hertel P., Hornung H., Cierpinski T. Femoral insertion of the ACL. Radiographic quadrant method. Am. J. Knee Surg., 1997, vol. 10, no. 1, pp. 14-21; discussion 21-22.

4. Bowers A.L., Bedi A., Lipman J.D., Potter H.G., Rodeo S.A., Pearle A.D., Warren R.F., Altchek D.W. Comparison of anterior cruciate ligament tunnel position and graft obliquity with transtibial and anteromedial portal femoral tunnel reaming techniques using high-resolution magnetic resonance imaging. Arthroscopy, 2011, vol. 27, no. 11, pp. 1511-1522. DOI:10.1016/j.arthro.2011.07.007

5. Chambat P. ACL tear. Orthop. Traumatol. Surg. Res., 2013, vol. 99, no. 1 Suppl., pp. S43-S52. DOI:10.1016/j.otsr.2012.11.012.

6. Chen Y., Chua K.H., Singh A., Tan J.H., Chen X., Tan S.H., Tai B.C., Lingaraj K. Outcome of Single-Bundle Hamstring Anterior Cruciate Ligament Reconstruction Using the Anteromedial Versus the Transtibial Technique: A Systematic Review and Metaanalysis. Arthroscopy, 2015, vol. 31, no. 9, pp. 1784-1794. DOI:10.1016/j.arthro.2015.06.001

7. Rayan F., Nanjayan S.K., Quah C., Ramoutar D., Konan S., Haddad F.S. Review of evolution of tunnel position in anterior cruciate ligament reconstruction. World J. Orthop., 2015, vol. 6, no. 2, pp. 252-262. DOI: 10.5312/wjo.v6.i2.252

8. Fineberg M.S., Zarins B., Sherman O.H. Practical considerations in anterior cruciate ligament replacement surgery. Arthroscopy, 2000, vol. 16, no. 7, pp. 715-724. DOI:10.1053/jars.2000.8951

9. Harner C.D., Marks P.H., Fu F.H., Irrgang J.J. Anterior cruciate ligament reconstruction: endoscopic versus two-incision technique. Arthroscopy, 1994, vol. 10, no. 5, pp. 502-512. DOI: 10.1016/s0749-8063(05)80004-0

10.Inderhaug E., Larsen A., Strand T., Waaler P.A., Solheim E. The effect of feedback from post-operative 3D CT on placement of femoral tunnels in single-bundle anatomic ACL reconstruction. Knee Surg. Sports Traumatol. Arthrosc., 2016, vol. 24, no. 1, pp. 154-160. DOI:10.1007/s00167-014-3355-0

11.Irrgang J.J., Anderson A.F., Boland A.L., Harner C.D., Kurosaka M., Neyret P., Richmond J.C., Shelborne K.D. Development and validation of the international knee documentation committee subjective knee form. Am. J. Sports Med., 2001, vol. 29, no. 5, pp. 600-613. DOI:10.1177/03635465010290051301

12.Kiapour A.M., Murray M.M. Basic science of anterior cruciate ligament injury and repair. Bone Joint Res., 2014, vol. 3, no. 2, pp. 20-31. DOI:10.1302/2046-3758.32.2000241

13.Kim S.J., Jung K.A., Song D.H. Arthroscopic double-bundle anterior cruciate ligament reconstruction using autogenous quadriceps tendon. Arthroscopy, 2006, vol. 22, no. 7, pp. 797.e1-797.e5. DOI:10.1016/j.arthro.2005.09.027

14.Kyung B.S., Kim J.G., Chang M., Jang K.M., Lee S.S., Ahn J.H., Wang J.H. Anatomic double-bundle reconstruction techniques result in graft obliquities that closely mimic the native anterior cruciate ligament anatomy. Am. J. Sports Med., 2013, vol. 41, no. 6, pp. 1302-1309. DOI:10.1177/0363546513484692

15.Robin B.N., Jani S.S., Marvil S.C., Reid J.B., Schillhammer C.K., Lubowitz J.H. Advantages and Disadvantages of Transtibial, Anteromedial Portal, and Outside-In Femoral Tunnel Drilling in Single-Bundle Anterior Cruciate Ligament Reconstruction: A Systematic Review. Arthroscopy, 2015, vol. 31, no. 7, pp. 1412-1417. DOI:10.1016/j.arthro.2015.01.018

16.Roos E.M., Roos H.P., Ekdahl C., Lohmander L.S. Knee injury and Osteoarthritis Outcome Score (KOOS) - validation of a Swedish version. Scand. J. Med. Sci. Sports, 1998, vol. 8, no. 6, pp. 439-448. DOI:10.1111/j.1600-0838.1998.tb00465.x

17.Kilinc B.E., Kara A., Oc Y., Celik H., Camur S., Bilgin E., Erten Y.T., Sahinkaya T., Eren O.T. Transtibial vs anatomical single bundle technique for anterior cruciate ligament reconstruction: A Retrospective Cohort Study. Int. J. Surg., 2016, vol. 29, pp. 62-69. DOI: 10.1016/j.ijsu.2016.03.025.

18.Stäubli H.U., Rauschning W. Tibial attachment area of the anterior cruciate ligament in the extended knee position. Anatomy and cryosections in vitro complemented by magnetic resonance arthrography in vivo. Knee Surg. Sports Traumatol. Arthrosc., 1994, vol. 2, no. 3, pp. 138-146. DOI:10.1007/BF01467915

19.Tegner Y., Lysholm J. Rating systems in the evaluation of knee ligament injuries. Clin. Orthop. Relat. Res., 1985, no. 198, pp. 43-49.

20.Zayats V.V., Dulaev A.K., Dydykin A.V., Ulianchenko I.N., Kolomoitsev A.V., Kovtun A.V. Analiz effektivnosti tekhnologii artroskopicheskoi plastiki perednei krestoobraznoi sviazki kolennogo sustava [Analysis of efficacy of the technologies of arthroscopic plasty of the anterior cruciate ligament of the knee]. Vestnik Khirurgii imeni I.I. Grekova [Grekov's Bulletin of Surgery], 2017, vol. 176, no. 2, pp. 77-82. (in Russian) DOI: 10.24884/0042-4625-2017-176-2-77-82

21.Wang H., Fleischli J.E., Hutchinson I.D., Zheng N.N. Knee moment and shear force are correlated with femoral tunnel orientation after single-bundle anterior cruciate ligament reconstruction. Am. J. Sports Med., 2014, vol. 42, no. 10, pp. $2377-2385$. DOI: $10.1177 / 0363546514541232$

22. Youm Y.S., Cho S.D., Lee S.H., Youn C.H. Modified transtibial versus anteromedial portal technique in anatomic single-bundle anterior cruciate ligament reconstruction: comparison of femoral tunnel position and clinical results. Am. J. Sports Med., 2014, vol. 42, no. 12, pp. 2941-2947. DOI:10.1177/0363546514551922

23.Zhang L., Jiang B., Sun J., Ma J., Zhang S., Liu X. [A comparative study of arthroscopic anterior cruciate ligament reconstruction via transtibial and transportal techniques]. Zhongguo Xiu Fu Chong Jian Wai Ke Za Zhi, 2019, vol. 33, no. 9, pp. 1077-1082. (in Chinese). DOI: 10.7507/1002-1892.201904124

24.Minguell J., Nuñez J.H., Reverte-Vinaixa M.M., Sallent A., Gargallo-Margarit A., Castellet E. Femoral tunnel position in chronic anterior cruciate ligament rupture reconstruction: randomized controlled trial comparing anatomic, biomechanical and clinical outcomes. Eur. J. Orthop. Surg. Traumatol., 2019, vol. 29, no. 7, pp. 1501-1509. DOI: 10.1007/s00590-019-02455-x 
25.Chen H., Tie K., Qi Y., Li B., Chen B., Chen L. Anteromedial versus transtibial technique in single-bundle autologous hamstring ACL reconstruction: a meta-analysis of prospective randomized controlled trials. J. Orthop. Surg. Res., 2017, vol. 12, no. 1 , pp. 167. DOI: $10.1186 / \mathrm{s} 13018-017-0671-3$

26.Zayats V.V. Tekhnologii anatomicheskoi rekonstruktsii perednei krestoobraznoi sviazki kolennogo sustava: vozmozhnosti i preimushchestva [Technologies of anatomic reconstruction of the knee anterior cruciate ligament: chances and benefits]. Uchenye Zapiski Sankt-Peterburgskogo Gosudarstvennogo Meditsinskogo Universiteta imeni akademika I.P. Pavlova [Scientific Notes of the State Pavlov St. Petersburg Medical University], 2018, vol. 25, no. 1, pp. 28-34. (in Russian). DOI: 10.24884/1607-4181-2018-25$1-28-34$

27.Golan E.J., Meredith S.J., Nakamura T., Rothrauff B.B., Fu F.H. Anatomic reconstruction of anterior cruciate ligament: concept, indication and its efficacy. AOJ (Annals of Joints), 2019, vol. 4, pp. 9. DOI: 10.21037/aoj.2018.12.11

28. Özer M., Özer H., Selek H., Baltacı G., Harput G., Taşkesen A., Çetinkaya M. Radiological and functional comparison of singlebundle anterior cruciate ligament reconstruction: transtibial versus anteromedial technique. Turk. J. Med. Sci., 2018, vol. 48, no. 3, pp. 455-461. DOI: 10.3906/sag-1702-119

29.MacDonald P., Kim C., McRae S., Leiter J., Khan R., Whelan D. No clinical differences between anteromedial portal and transtibial technique for femoral tunnel positioning in anterior cruciate ligament reconstruction: a prospective randomized, controlled trial. Knee Surg. Sports Traumatol. Arthrosc., 2018, vol. 26, no. 5, pp. 1335-1342. DOI: 10.1007/s00167-017-4664-x

30.Taşdemir Z., Gülabi D., Sağlam F., Tokgöz Özal S., Elmalı N. Does the anteromedial portal provide clinical superiority compared to the transtibial portal in anterior cruciate ligament reconstruction in nonprofessional athletes in short-term follow-up? Acta Orthop. Traumatol. Turc., 2015, vol. 49, no. 5, pp. 483-491. DOI: 10.3944/AOTT.2015.15.0016

31.Zbrojkiewicz D., Vertullo C., Grayson J.E. Increasing rates of anterior cruciate ligament reconstruction in young Australians, 20002015. Med. J. Aust., 2018, vol. 208, no. 8, pp. 354-358. DOI: 10.5694/mja17.00974

32.So S.Y., Suh D.W., Lee S.S., Jung E.Y., Ye D.H., Ryu D., Kwon K.B., Wang J.H. Revision Anterior Cruciate Ligament Reconstruction After Primary Anatomic Double-Bundle Anterior Cruciate Ligament Reconstruction: A Case Series of 40 Patients. Arthroscopy, 2020, vol. 36, no. 2, pp. 546-555. DOI: 10.1016/j.arthro.2019.08.038

Received: 25.02 .2020

\section{Information about the authors:}

1. Vitaliy V. Zayats, M.D., Ph.D.,

Pavlov First St. Petersburg State Medical University, Saint Petersburg, Russian Federation, Email: zaiatc.vitalii@gmail.com

2. Alexander K. Dulaev, M.D., Ph.D., Professor,

Pavlov First St. Petersburg State Medical University, Saint Petersburg, Russian Federation, Email: akdulaev@gmail.com

3. Andrey V. Dydykin, M.D., Ph.D., Professor,

Pavlov First St. Petersburg State Medical University, Saint Petersburg, Russian Federation, Email: dydykinav@mail.ru

4. Ivan N. Ulyanchenko,

Pavlov First St. Petersburg State Medical University, Saint Petersburg, Russian Federation, Email: yluanchenko@gmail.com 